Finisterra, XXXV, 70, 2000, pp. 131-132

\title{
ÉTUDES DE GÉOGRAPHIE HUMAINE EN AFRIQUE OCCIDENTALE
}

Paul PÉlissier 1

Heureuse initiative que celle de Suzanne Daveau qui nous offre, en ce volume élégamment présenté ${ }^{2}$, l'essentiel de ses publications, jusqu'ici dispersées, consacrées à la géographie humaine de l'Afrique occidentale.

Géographe complète, notre collègue ne s'est pas davantage limitée au thème central de ses préoccupations, la géomorphologie tropicale, quand elle enseignait à Dakar, qu'elle n'a abandonné l'Afrique en s'installant à Lisbonne et en faisant alors du Portugal son nouveau champ de recherche. Cette double fidélité à une géographie globale et à l'Afrique nous vaut deux types de travaux répondant aux deux étapes majeures du parcours scientifique de l'auteur: d'une part des textes issus de recherches sur le terrain, d'autre part des articles résultant de l'analyse des écrits portugais de l'époque des Grandes Découvertes.

Au premier type de travaux se rattachent sept articles qui relèvent euxmêmes de deux ordres de recherches. Le premier est directement le fruit d'observations personnelles sur les relations des sociétés rurales avec le milieu sahélien, en particulier celles auxquelles les grands escarpements qui rompent la monotonie générale de l'Ouest africain servent de base territoriale, naguère de refuge. Les articles suivants illustrent le versant saharien des activités de Suzanne Daveau, d'abord sa participation à la connaissance du milieu aujourd'hui désertique où se situait, au Haut Moyen Âge, la ville d'Aoudaghost, et d'autre part une «tentative d'archéologie du paysage» qui retrouve, au cœur de l'actuelle Mauritanie, les traces d'une agriculture sahélienne d'un modèle comparable à celle que pratiquent aujourd'hui les Dogons de la falaise de Bandiagara (Mali).

La seconde partie de l'ouvrage est faite d'études élaborées à partir de textes consécutifs à la découverte des côtes africaines par les navigateurs portugais. Il s'agit non pas d'apporter de nouvelles pierres à la connaissance de cette découverte, mas de tirer des récits et chroniques de ces voyages des données susceptibles de dessiner progressivement une sorte de paléo-géographie

1 Professeur émérite de l'Université de Nanterre (France).

2 Daveau, Suzanne, A Descoberta da África Ocidental. Ambiente natural e sociedades, Comissão Nacional para a Comemoração dos Descobrimentos Portugueses, Lisboa, 1999, 299 p. 
de l'hinterland accessible aux découvreurs. Recherches pionnières dont la multiplication pourrait déboucher sur l'esquisse d'évolutions historiques retrouvant les préoccupations les plus contemporaines, telles d'éventuelles oscillations climatiques depuis le XVe siècle et leurs effets sur le peuplement des régions les plus vulnérables à la moindre perturbation, c'est-à-dire les plus sèches.

Assorti d'une bibliographie synthétique et d'un riche index analytique, et illustré de clichés personnels saisissants, cet ouvrage témoigne que la spécialisation n'est pas incompatible avec une authentique géographie. D'un style sobre et clair, il apporte aux étudiants une initiation directe à la connaissance de l'Afrique saharo-sahélienne et ouvre aux chercheurs de nouvelles pistes pour l'interprétation des si précieux documents portugais de l'époque des Découvertes. 